\title{
Adsorption of Fe(III) from Aqueous Solution by Linde Type-A Zeolite
}

\author{
Saeedeh Hashemian*, Seyed Hossein Hosseini, Hamila Salehifar, Khaterah Salari \\ Chemistry Department, Yazd Branch, Islamic Azad University, Yazd, Iran \\ Email: *sa_hashemian@yahoo.com
}

Received May 18, 2013; revised June 20, 2013; accepted July 5, 2013

Copyright (C) 2013 Saeedeh Hashemian et al. This is an open access article distributed under the Creative Commons Attribution License, which permits unrestricted use, distribution, and reproduction in any medium, provided the original work is properly cited.

\begin{abstract}
Linde Type-A (LTA) zeolite was prepared from sodium aluminate and sodium metasilicate by hydrothermal process precursors. Sodium metasilicate prepared from molten $\mathrm{NaOH}$ and $\mathrm{SiO}_{2}$. The zeolite was characterized by FTIR, XRD, XRF and SEM. The adsorption of Fe(III) from aqueous solution by zeolite A was studied. Different parameters like contact time, $\mathrm{pH}$ and concentration of iron were investigated. The results show that at contact time of $60 \mathrm{~min}$ and $\mathrm{pH}$ of 6 maximum adsorption of iron onto zeolite was observed. The kinetic data was analyzed using pseudo-first-order and pseudo-second-order kinetic models. The adsorption kinetics of Fe(III) were fitted well with the pseudo-second-order kinetic model.
\end{abstract}

Keywords: Adsorption; LTA Zeolite; Sodium Metasilicate; Fe(III) Removal

\section{Introduction}

Porous solids are interest of researcher and scientist because of their ability to interact with atoms, ions and molecules not only at their outer surfaces, but also throughout the inner porous network. This involves ion exchange, adsorption (for separation) and catalysis; many of these processes actually benefit from the high order that can be achieved in solids such as zeolites. Zeolites represent one of the most commercially relevant categories of crystalline microporous solids. Zeolites are hydrated aluminosilicates of the alkaline and alkaline-earth metals with fully cross-linked open framework structures made up of corner sharing $\mathrm{SiO}_{4}$ and $\mathrm{AlO}_{4}$ tetrahedral. There are about 40 natural zeolites which have been identified during the past 200 years and more than 150 zeolites have been synthesized. For synthetic zeolites; the most common are zeolites A, X, Y andZSM-5. Zeolites, with their permanent negative charges as well as the interconnection of channels and cages that run through their secondary framework structure, are efficient adsorbents for positively charged pollutants such as heavy metals [1-3]. Both natural and synthetic zeolites are used commercially because of their unique adsorption, ionexchange, molecular sieve and catalytic properties.

The application of zeolites to environmental pollution control in terms of heavy metal removal has received ${ }^{*}$ Corresponding author. very little attention, possibly due to the low $\mathrm{pH}$ solution that is often necessary [4-10]. Adsorption is a special characteristic of zeolites which is usually quite a complex process, generally involving much more than simple ion exchange into the pore openings of the ion exchanger. The amount of metal ion to be adsorbed is strongly affected by nature and concentration of the counter ion (metal ion), $\mathrm{pH}$, metal solubility, presence of competing and complexing ions $[11,12]$. Since it is considered to be a particularly effective technique, adsorption is the preferred method for heavy metal removal.

In this study, first Linde Type-A zeolite was synthesized, and then the adsorption behavior of Fe(III) by zeolite was studied.

\section{Experimental}

\subsection{Materials and Methods}

Silicon Dioxide (99.8 wt\%) was used as a silica source (Prepared from Glass Company Mazroof Yazd). Sodium aluminate was used as aluminum source (Riedel), soudium hydroxide, $\mathrm{FeCl}_{3} \cdot 6 \mathrm{H}_{2} \mathrm{O}$ and other compound were obtained from Merck. All compounds were use as received without any purification.

The crystalline structure of the synthesized zeolite seeds was determined by FTIR, XRF and XRD. FTIR spectra of synthesized LTA zeolites were recorded with 
spectrophotometer (Bruker, Tensor27) using pellet technique. A mixture of $5.0 \mathrm{mg}$ LTA zeolite and $200.0 \mathrm{mg}$ of $\mathrm{KBr}$ were pressed into a disk for IR measurement. XRD was carried out on a PW3719 Philips X'Pert diffractometer using $\mathrm{Cu} \mathrm{K} \alpha\left(\lambda=1.54^{\circ} \mathrm{A}\right)$ radiation, operated at 30 $\mathrm{mA}$ and $40 \mathrm{kV}$. The diffraction patterns of the products were obtained for a $2 \theta$ range of $0^{\circ}-50^{\circ}$. Fluorescence Bruker S4 Pioneer XRF wavelength dispersive spectrometer equipped with an array of up to 8 analyzing crystals and fitted with an Rh X-ray tube target was used. A vacuum was used as the medium of analyses to avoid interaction of X-rays with air particles. Scanning electron microscopy (SEM) was carried by XL30 Philips.

\subsection{Preparation of Zeolite}

Sodium metasilicate is the most stable of silicic acid sodium salts and can be prepared from molten or hot aqueous $\mathrm{NaOH}$ and $\mathrm{SiO}_{2}$ (preferably in powder, so that it has more reaction area). The reaction is as follows:

$$
2 \mathrm{NaOH}+\mathrm{SiO}_{2} \rightarrow \mathrm{Na}_{2} \mathrm{SiO}_{3}+\mathrm{H}_{2} \mathrm{O}
$$

The crucible is loaded with $10 \mathrm{~g} \mathrm{NaOH}$ and 7.6 gsilicon dioxide powder, and completely mixed together. Crucible placed in the furnace for 30 minutes in air at 1073 $\mathrm{K}$ to reaction completed. Greenish white powder (Sodium metasilicate) isobtained at $25^{\circ} \mathrm{C}$. The LTA was prepared by the procedure reported [13].

First, sodium hydroxide (0.72 g) was dissolved in 80 $\mathrm{ml}$ of distilled water. This solution was divided into two parts. To the first part of the solution of sodium aluminate $(8.25 \mathrm{~g})$ was added. To the second part, (15.48 g) sodium metasilicate was added. These mixtures were stirred for $30 \mathrm{~min}$. Then the two parts were poured simultaneously into a teflon container, resulting in the formation of a creamy gel. The Teflon container was sealed in an autoclave (hydrothermal bomb) and heated at $100^{\circ} \mathrm{C}$ for 24 hours. After cooling, the precipitate was collected by filtration. The obtained white precipitate was washed with water DI until the $\mathrm{pH}$ value of the wash liquor decreased from 13 to 10 and then the produced materials were dried overnight at $100^{\circ} \mathrm{C}$.

\section{Results and Discussion}

\subsection{Characterization of LTA Zeolite}

FTI R spectra of LTA zeolite is shown in Figure 1. The bands at 450 to $1200 \mathrm{~cm}^{-1}$ are known to assignable to Si-O-Al, Si-O-Si, Si-O, Si-Al and T-O species [13]. In the other hand, the broad bands at 3350 to $3700 \mathrm{~cm}^{-1}$ are attributed to $\mathrm{Si}-\mathrm{OH}, \mathrm{Si}-\mathrm{OH}-\mathrm{Al}$ and $-\mathrm{OH}$ hydroxyl groups. The band at $668 \mathrm{~cm}^{-1}$ is known to assignable to $\mathrm{Si}-\mathrm{O}-\mathrm{M}$ where Misthe exchangeable $\mathrm{Na}^{+}$ion metal species. The absorption band at $668 \mathrm{~cm}^{-1}$ in LTA is visible which is in corporate with $\mathrm{Na}$ atoms in the zeolite framework [12].
XRD patterns of LTA zeoliteis shown in Figure 2. $\mathrm{XRD}$ result is shown high purity and a good crystallinity of zeolite. These results are in good agreement with those reported in the literature [12]. After indexation of XRD patterns of prepared zeolites, all diffraction planes (hkl) correspond to LTA phases. The synthesis product matched the characteristic peaks of zeolite A at $2 \theta$ values of $7.2^{\circ}, 10.3^{\circ}, 12.6^{\circ}, 16.2^{\circ}, 21.8^{\circ}, 24^{\circ}, 26.2^{\circ}, 27.2^{\circ}, 30^{\circ}$, $30.9^{\circ}, 31.1^{\circ}, 32.6^{\circ}, 33.4^{\circ}$ and $34.3^{\circ}$ that were reported previously by Treacy and Higgins [14]. The results of $\mathrm{X}$-ray Fluorescence (XRF) analysis is shown in Table 1. The XRF is offered molar ratio of $\mathrm{Si} / \mathrm{Al}$ about 1 for LTA zeolite. Scanning electronic micrographs show the cubic shape of particles for LTA zeolite. Figure 3 shows the SEM image of zeolite.

\subsection{Adsorptive Properties of the LTA Zeolite}

\subsubsection{Effect of $\mathrm{pH}$ on the Adsorption of $\mathrm{Fe}(\mathrm{III})$}

The effect of solution $\mathrm{pH}$ is important factor for adsorption process. A solution containing 70 and $100 \mathrm{mg} \cdot \mathrm{L}^{-1}$ of $\mathrm{Fe}(\mathrm{III})$ was prepared using deionized water. The $0.1 \mathrm{~g}$ of zeolite and $30 \mathrm{~mL}$ of $\mathrm{Fe}(\mathrm{III})$ was used. The $\mathrm{pH}$ was adjusted to a range of $2-7$. The sample was shaken for 60 min on a shaker. The suspension was then filtered. Metal ion concentrations in the filtrate were analyzed using a varian 220 atomic absorption spectrometer. The results show that, the adsorption capacity of LTA zeolite for adsorption of $\mathrm{Fe}(\mathrm{III})$ increased with increasing the $\mathrm{pH}$ of the medium from 2 to 6 , but it is nearly constant from 6 to 8 , and after than decrease to $\mathrm{pH}$ of 10 . Therefore, the maximum adsorption capacity was observed at $\mathrm{pH} 6$ (Figure 4). pHs more than 8 case the precipitation of iron hydroxide.

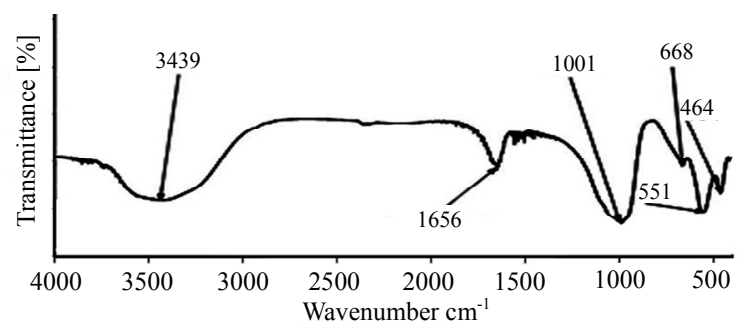

Figure 1. FTI R spectra of LTA zeolite.

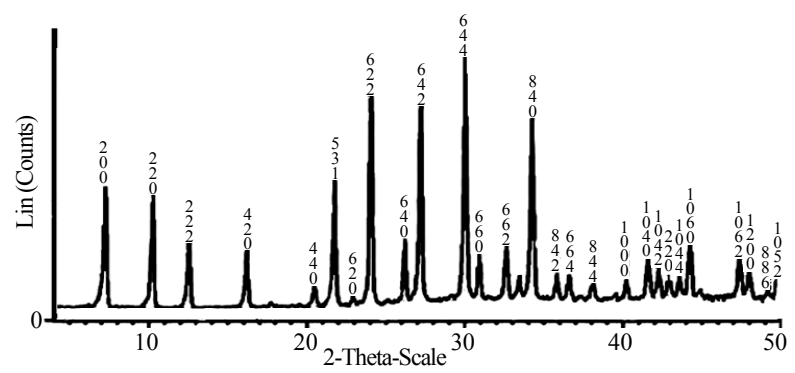

Figure 2. XRD pattern of LTA zeolite. 
Table 1. XRF analysis of LTA zeolite.

\begin{tabular}{cc}
\hline Compound & Concentration $(\% \mathrm{~W} / \mathrm{W})$ \\
\hline $\mathrm{SiO}_{2}$ & 32.86 \\
$\mathrm{Al}_{2} \mathrm{O}_{3}$ & 30.48 \\
$\mathrm{Na}_{2} \mathrm{O}$ & 19.28 \\
$\mathrm{~K}_{2} \mathrm{O}$ & 0.043 \\
$\mathrm{CaO}$ & 0.042 \\
$\mathrm{Fe}_{2} \mathrm{O}_{3}$ & 0.038 \\
$\mathrm{CO}$ & 0.006 \\
$\mathrm{LOI}^{*}$ & 17.22 \\
Total & 99.97 \\
\hline
\end{tabular}

${ }^{*}$ Loss on ignition $\left(1000^{\circ} \mathrm{C}, 2 \mathrm{~h}\right)$.

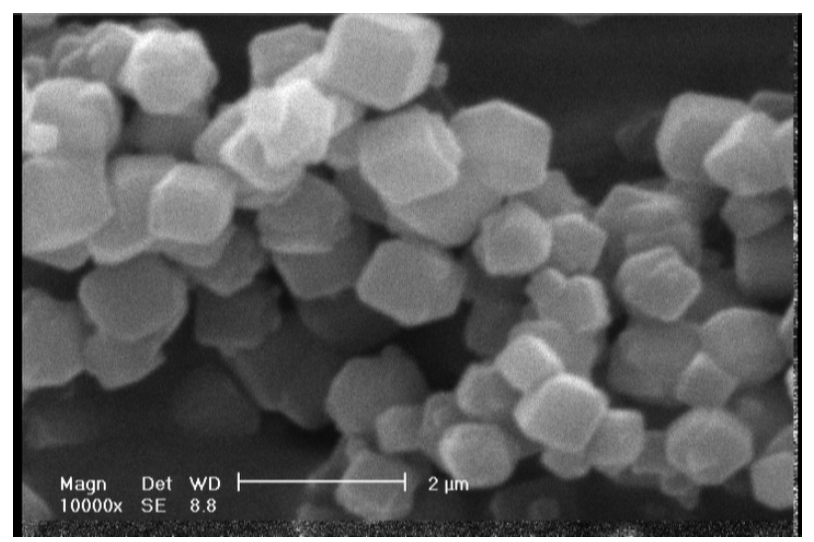

Figure 3. SEM image of LTA zeolite.

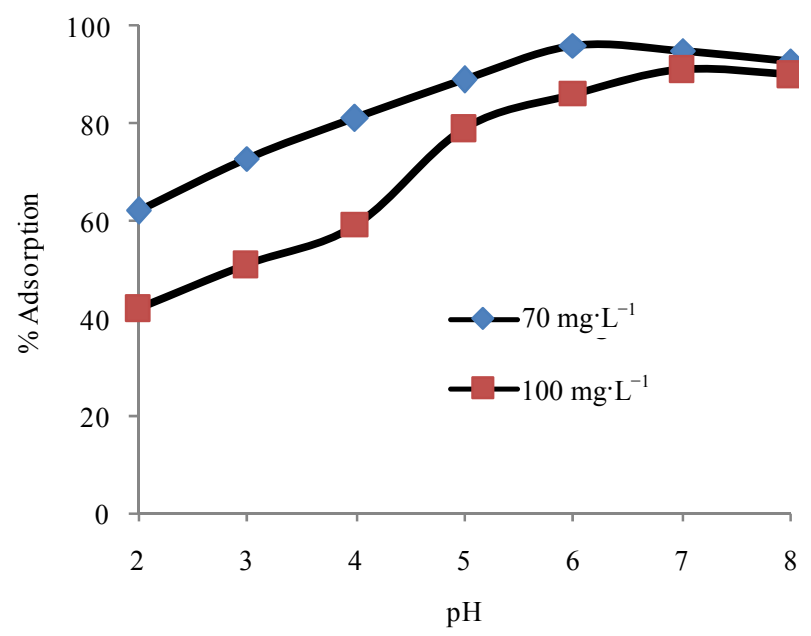

Figure 4. Effect of $\mathrm{pH}$ on the adsorption of $\mathrm{Fe}$ (III) onto LTA zeolite.

\subsubsection{Effect of Contact Time}

The effect of contact time on adsorption of Fe(III) with concentration 70 and $100 \mathrm{mg} \cdot \mathrm{L}^{-1}$ was studied. The results show that initial adsorption was rapid due to the adsorption of iron onto exterior surface, after that metal ions enter into pores (interior surface), relatively slow process. The adsorption rate decreased substantially with time further than $60 \mathrm{~min}$. The adsorption process was attained to equilibrium at $90 \mathrm{~min}$ of contact time. The increasing of shaking time more than 90 min has no significant effect on adsorption of metal ions. Therefore, the best shaking time is $90 \mathrm{~min}$ at which adsorption of iron metal is $92 \%$ and $96 \%$, for $\mathrm{Fe}$ (III) 100 and 70 $\mathrm{mg} \cdot \mathrm{L}^{-1}$. Figure 5 shows the effect of contact time for adsorption of $\mathrm{Fe}(\mathrm{III})$ onto LTA zeolite.

\subsection{Kinetics of Adsorption}

The kinetic data of the adsorption of Fe(III) onto LTA zeolite was evaluated using pseudo-first order and pseudosecond-order kinetic models. The pseudo-first order model assumes that the rate of change of solute uptake with time is directly proportional to difference in saturation concentration and amount of solid uptake with time [15].

$$
\ln \left(q_{e}-q_{t}\right)=\ln q_{e}-k_{1} t
$$

where $q_{e}$ and $q_{t}$ are the amounts of dye adsorbed per unite mass of the adsorbent $\left(\mathrm{mg} \cdot \mathrm{g}^{-1}\right)$ at equilibrium and time $t$, respectively and $k_{1}$ is the rate constant of adsorption $\left(\min ^{-1}\right)$. When $\ln \left(q_{e}-q_{t}\right)$ was plotted against time, a straight line should be obtained with a slope of $k_{1}$, if the first order kinetics is valid.

The pseudo-second order model as developed by Ho and McKay $[15,16]$ has the following form:

$$
t / q_{t}=t / q_{e}+1 /\left(k_{2} q_{e}^{2}\right)
$$

where $q_{e}$ and $q_{t}$ represent the amount of dye adsorbed $\left(\mathrm{mg} \cdot \mathrm{g}^{-1}\right)$ at equilibrium and at any time. $k_{2}$ in the rate constant of the pseudo-second order equation $\left(\mathrm{g} \cdot \mathrm{mg}^{-1}\right.$ $\left.\min ^{-1}\right)$. A plot of $t / q$ versus time $(t)$ would yield a line with a slope of $1 / q_{e}$ and an intercept of $1 /\left(k_{2} q_{e}^{2}\right)$, if

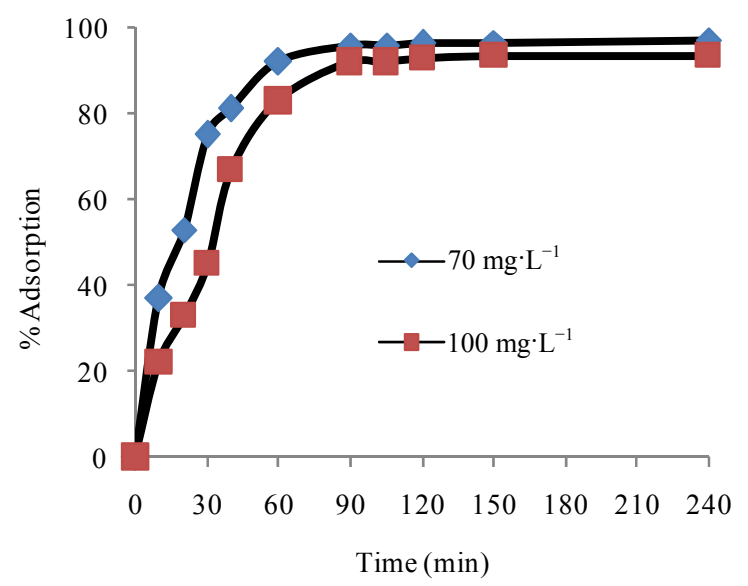

Figure 5. Effect of contact time on the adsorption of Fe(III) onto LTA zeolite. 
Table 2. Pseudo-first order and Pseudo-second order kinetics rate constants for Iron(III) on zeolite LTA.

\begin{tabular}{cccc}
\hline \multicolumn{2}{c}{ First order kinetic model } & \multicolumn{2}{c}{ Second order kinetic model } \\
\hline $\mathrm{R}^{2}$ & $k_{1}\left(\mathrm{~min}^{-1}\right)$ & $\mathrm{R}^{2}$ & $k_{2}\left(\mathrm{~g} \cdot \mathrm{mg}^{-1} \cdot \mathrm{min}^{-1}\right)$ \\
0.697 & 0.03 & 0.976 & $2 \times 10^{-5}$ \\
\hline
\end{tabular}

the second order model is a suitable expression.

From the plot between $\ln \left(q_{e}-q_{t}\right)$ versus time $t$ and the plot of $t / q$ versus time $t$, the rate constant of firs and second order of adsorption, also $\mathrm{R}^{2}$ were determined. Table 2 shows the kinetic parameters of adsorption of Fe (III) onto LTA zeolite. The kinetic model with a higher correlation coefficient $\mathrm{R}^{2}$ was selected as the most suitable one. Results are shown the adsorption of Fe(III) onto LTA zeolite is followed by pseudo-second order.

\section{Conclusion}

LTA zeolite was successfully obtained in two steps. FTIR, XRD and SEM results confirmed the formation of crystalline form of LTA zeolite. The LTA zeolite was used for iron removal from water. Results show that at contact time $60 \mathrm{~min}$ and $\mathrm{pH}$ of 6 , the maximum iron removal falls down.

\section{Acknowledgments}

The authors wish to thank Islamic Azad University of Yazd (IAUY) for the financial support of this work. Also, thank co-workers and technical staff in the chemical department help during various stages of this work.

\section{REFERENCES}

[1] A. A.Ismail, R. M. Mohamed, I. A. Ibrahim, G. Kini and B. Koopman, "Synthesis Optimization and Characterization of Zeolite A and Its Ion-Exchange Properties," Colloids and Surfaces A, Vol. 366, No. 1-3, 2010, pp. 80-87. doi:10.1016/j.colsurfa.2010.05.023

[2] R. A. Rakoczy and Y. Traa, "Nanocrystalline Zeolite A: Synthesis, Ion Exchange and Dealumination," Microporous and Mesoporous Materials, Vol. 60, No. 1-3, 2003, pp. 69-78. doi:10.1016/S1387-1811(03)00318-4

[3] A. Huang and W. Yang, "Hydrothermal Synthesis of NaA Zeolite Membrane Together with Microwave Heating and Conventional Heating," Materials Letters, Vol. 61, No. 29, 2007, pp. 5129-5132. doi:10.1016/j.matlet.2007.04.017

[4] E. Basaldella, P. G. Vázquez, F. Iucolano and D. Caputo, "Chromium Removal from Water Using LTA Zeolites: Effect of $\mathrm{pH}$," Journal of Colloid and Interface Science, Vol. 313, No. 2, 2007, pp. 574-581. doi:10.1016/j.jcis.2007.04.066
[5] R. M. Mohamed, A. A. Ismail, G. Kini, I. A. Ibrahim and B. Koopman, "Synthesis of Highly Ordered Cubic Zeolite A and Its Ion-Exchange Behavior," Colloids and Surfaces $A$, Vol. 348, No. 1-3, 2009, pp. 87-92. doi:10.1016/j.colsurfa.2009.06.038

[6] H. R. Tashauoei, A. Movahedian , H. Kamali, M. Amin and M. Nikaeen, "Removal of Hexavalent Chromium(VI) from Aqueous Solutions Using Surface Modified Nanozeolite A," International Journal of Environmental Research, Vol. 4, No. 3, 2010, pp. 491-499.

[7] K. S. Hui, C. Y. H. Chao and S. C. Kot, "Removal of Mixed Heavy Metal Ions in Wastewater by Zeolite 4A and Residual Products from Recycled Coal Fly Ash," Journal of Hazardous Materials, Vol. 127, No. 1-3, 2005, pp. 89-101. doi:10.1016/j.jhazmat.2005.06.027

[8] M. A. Hopa, Z. Yilmaz and H. Güler, "The Effect of Alkali Concentration and Solid/Liquid Ratio on the Hydrothermal Synthesis of Zeolite NaA from Natural Kaolinite," Microporous and Mesoporous Materials, Vol. 86, No. 1-3, 2005, pp. 176-183.

doi:10.1016/j.micromeso.2005.07.008

[9] B. Bayati, A. A. Babaluo and R. Karimi, "Hydrothermal Synthesis of Nanostructure NaA Zeolite: The Effect of Synthesis Parameters on Zeolite Seed Size and Crystallinity," Journal of the European Ceramic Society, Vol. 28, No. 14, 2008, pp. 2653-2657. doi:10.1016/j.jeurceramsoc.2008.03.033

[10] E. Erdem, N. Karapinar and R. Donat, "The Removal of Heavy Metal Cations by Natural Zeolites," Journal of Colloid and Interface Science, Vol. 280, No. 2, 2004, pp. 309-314. doi:10.1016/j.jcis.2004.08.028

[11] "The CRC Handbook of Chemistry and Physics," 85th Edition, CRC Press.

[12] J. Kugbe, N. Matsue and T. Henmi, "Synthesis of Linde Type A Zeolite-Goethite Nanocomposite as an Adsorbent for Cationic and Anionic Pollutants," Journal of Hazardous Materials, Vol. 164, No. 2-3, 2009, pp. 929-935. doi:10.1016/j.jhazmat.2008.08.080

[13] R. W. Thompson and M. J. Huber, "Analysis of the Growth of Molecular Sieve Zeolite NaA in a Batch Precipitation System," Journal of Crystal Growth, Vol. 56, No. 3, 1982, pp. 711-722. doi:10.1016/0022-0248(82)90056-2

[14] M. J. Treacy and J. B. Higgins, "Collection of Simulated XRD Powder Patterns for Zeo-Iites," 4th Edition, Elsevier, Amsterdam, 2001, p. 379.

[15] Y. S. Ho and G. McKay, "Sorption of Dye from Aqueous Solution by Peat," Chemical Engineering Journal, Vol. 70, No. 2, 1998, pp. 115-124.

[16] Y. S. Ho and G. McKay, "Pseudo-Second Order Model for Sorption Processes," Process Biochemistry, Vol. 34, No. 5, 1999, pp. 451-465. doi:10.1016/S0032-9592(98)00112-5 